\title{
Performed Observation Focal Duration
}

National Cancer Institute

\section{Source}

National Cancer Institute. Performed Observation Focal Duration. NCI Thesaurus. Code C93934.

The quantity of time in which the observation result is held to be true. 